https://helda.helsinki.fi

\title{
Time course of motor gains induced by Music-Supported Therapy after stroke : An exploratory case study
}

\section{Grau-Sánchez, Jennifer}

2017

Grau-Sánchez , J , Ramos , N , Duarte , E , Särkämö , T \& Rodriguez-Fornells , A 2017 , '

Time course of motor gains induced by Music-Supported Therapy after stroke : An

exploratory case study ' , Neuropsychology , vol. 31 , no. 6 , pp. 624-635 . https://doi.org/10.1037/neu0000355

http://hdl.handle.net/10138/311675

https://doi.org/10.1037/neu0000355

acceptedVersion

Downloaded from Helda, University of Helsinki institutional repository.

This is an electronic reprint of the original article.

This reprint may differ from the original in pagination and typographic detail.

Please cite the original version. 


\title{
Time course of motor gains induced by Music-Supported Therapy after stroke: An exploratory case study
}

\author{
Jennifer Grau-Sánchez and Neus Ramos-Escobar \\ Department of Basic Psychology, University of Barcelona \\ Esther Duarte \\ Physical Medicine and Rehabilitation Department, Hospitals del Mar i l'Esperança, Parc Salut Mar \\ Autonomous University of Barcelona \\ Teppo Särkämö \\ Institute of Behavioural Sciences, University of Helsinki \\ Antoni Rodríguez-Fornells \\ Department of Basic Psychology, University of Barcelona \\ Catalan Institute for Research and Advanced Studies
}

\begin{abstract}
Author Note
Jennifer Grau-Sánchez, Cognition and Brain Plasticity Unit, Department of Basic Psychology, University of Barcelona; Neus Ramos-Escobar, Cognition and Brain Plasticity Unit, Department of Basic Psychology, University of Barcelona; Esther Duarte Physical Medicine and Rehabilitation Department, Hospitals del Mar i l'Esperança, Parc Salut Mar; Rehabilitation Research Group, Biomedical Research Institute Hospital del Mar, Autonomous University of Barcelona; Teppo Särkämö, Cognitive Brain Research Unit, Institute of Behavioural Sciences, University of Helsinki. Antoni Rodríguez-Fornells, Cognition and Brain Plasticity Unit, Department of Basic Psychology, University of Barcelona; Catalan Institute for Research and Advanced Studies.

This study was supported by the program RecerCaixa. JGS, NR, ED and ARF designed the study, JGS and NR performed research, and JGS and TS analyzed the data. The manuscript was written bu JGS and reviewed by all the authors.

Correspondence concerning this article should be addressed to Antoni Rodríguez-Fornells, Cognition and Brain Plasticity Group (IDIBELL), Campus Bellvitge , Feixa Llarga, s/n (08907), L'Hospitalet de Llobregat, Spain. Email: antoni.rodriguez@icrea.es
\end{abstract}


Running head: TIME COURSE OF MOTOR GAINS INDUCED BY MUSIC-SUPPORTED THERAPY

AFTER STROKE: AN EXPLORATORY CASE STUDY

OBJECTIVE: Previous studies have shown that Music-Supported Therapy (MST) can improve the motor function and promote functional neuroplastic changes in motor areas. However, the time course of the motor gains across MST sessions and treatment periods remain unknown. This study aimed to explore the progression of the rehabilitation of motor deficits in a chronic stroke patient during 7 months.

METHOD: A reversal design (ABAB) where no treatment was provided in the $A$ periods and MST was applied in the $B$ periods was implemented in a chronic stroke patient. Each period comprised 4 weeks and an extensive evaluation of the motor function using clinical motor tests and 3D movement analysis was performed weekly. Moreover, during the MST periods, a keyboard task was recorded daily. A follow-up evaluation was performed 3 months after the second MST treatment.

RESULTS: Improvements were seen during the first sessions in the keyboard task but clinical gains were noticeable only at the end of the first treatment and during the second treatment period. These gains were maintained in the follow-up evaluation.

CONCLUSIONS: This is the first study examining the pattern of motor recovery progression in MST, evidencing that gradual and continuous motor improvements are possible with the repeated application of MST training. Besides, fast-acquisition in specific motor abilities was observed at the beginning of the MST training but generalization of these improvements to other motor tasks took place at the end or when another treatment period is provided.

Keywords: Stroke, motor rehabilitation, Music-Supported Therapy 
Running head: TIME COURSE OF MOTOR GAINS INDUCED BY MUSIC-SUPPORTED THERAPY AFTER STROKE: AN EXPLORATORY CASE STUDY

54

\section{Public significance statement:}

55 This study examined the progression of the motor and functional gains of a chronic stroke patient treated with Music-Supported Therapy during two different periods. The patient showed significant

57 improvements in the clinical motor domain at the end of the first and second treatment periods. Some 58 of these gains were maintained over time in a follow-up evaluation performed at 3 months. 
Running head: TIME COURSE OF MOTOR GAINS INDUCED BY MUSIC-SUPPORTED THERAPY AFTER STROKE: AN EXPLORATORY CASE STUDY

\section{Time course of motor gains induced by Music-Supported Therapy after stroke: a case study}

Motor deficits are the most common outcome after a stroke and can include weakness, spasticity, slowness, or tremor (Pomeroy et al., 2011). Around 75\% of stroke patients present paresis of the contralateral upper extremity (UE) (Rathore, Hinn, Cooper, Tyroler, \& Rosamond, 2002) which can affect coordination, precision and dexterity, limiting the performance of activities of daily living (Langhorne, Bernhardt, \& Kwakkel, 2011). Overall, motor deficits have a fundamental impact on the lives of stroke patients, restricting their participation in various family, work, and leisure contexts and markedly reducing their quality of life (Visser et al., 2015).

The rehabilitation of motor deficits aims to facilitate plastic changes in the brain to restore lost functions (Cramer et al., 2011) through the use of tasks involving massed practice (Carmichael \& Krakauer, 2013), shaping, modeling and feedback to promote skill learning (Krakauer, 2006). In this context, it is important that the tasks used in the rehabilitation process are experienced as motivating by patients, having real world relevance (Timmermans, Spooren, Kingma, \& Seelen, 2010). In this vein, music has emerged as a very promising tool in neurorehabilitation since musical activities place unique demands on the nervous system (Zatorre, Chen, \& Penhune, 2007) and can be adapted to utilize many basic principles of neurorehabilitation.

Music-Supported Therapy (MST) was developed for stroke patients by Schneider and colleagues (Schneider, Schönle, Altenmüller, \& Münte, 2007) with the aim of enhancing the hemiparesis of the UE through musical playing. Recent studies in both acute and chronic stroke patients have shown that MST can improve UE motor deficits, including gains in dexterity and movement kinematics (Altenmüller, Marco-Pallares, Münte, \& Schneider, 2009; Rojo et al., 2011).

MST is aimed at promoting neuroplastic changes similar to those occurring during and after normal motor skill learning and training. Learning to play an instrument promotes functional and structural changes in motor and sensory regions of the brain as seen in musicians as well as in naïve individuals 
Running head: TIME COURSE OF MOTOR GAINS INDUCED BY MUSIC-SUPPORTED THERAPY AFTER STROKE: AN EXPLORATORY CASE STUDY

receiving intensive musical training (Altenmüller \& Schlaug, 2015; Schlaug, 2015). In chronic stroke patients, Ripollés and colleagues (Ripollés et al., 2015) recently observed neuroplastic changes induced by MST, showing a reduction of activation in contralesional motor cortical areas during a simple motor task, resulting in a motor activation pattern more similar to that of a normally functioning brain. Moreover, an increase in the excitability of the sensorimotor cortex as well as changes in the cortical motor representation have been reported in subacute and chronic stroke patients treated with MST (Amengual et al., 2013; Grau-Sánchez et al., 2013).

One of the key features of MST may be the role of the auditory feedback in the training since music playing requires the interaction of auditory-motor networks. It has been widely observed that auditory-motor co-activation takes place not only during musical performance but also when listening to musical pieces or when playing a silent instrument (Bangert et al., 2006; Baumann, Koeneke, Meyer, Lutz, \& Jäncke, 2005). To account for this effect, a feedforward and feedback model has been proposed where the internal motor representation and the auditory expectation might influence the final motor output and also evaluate the performance of on-line movements (Zatorre et al., 2007). This sensory-motor interplay seems to be disrupted in stroke patients (Rodriguez-Fornells et al., 2012). However, it has been found that the activity of the premotor cortex, supplementary motor area, and precentral gyrus increases when stroke patients treated with MST listen to the trained melodies. Moreover, functional connectivity analysis has revealed that this co-activation of auditory and motor regions could be re-established in chronic stroke patients after MST (Ripollés et al., 2015). In these studies investigating the plastic changes associated to MST (Amengual et al., 2013; GrauSánchez et al., 2013; Ripollés et al., 2015), a proper control patient group treated with a different therapy has not been assessed and therefore, it is not possible to establish a direct link between the implications of auditory-motor circuits in motor recovery. Further research is needed to elucidate the mechanisms of neural plasticity promoted by MST. 
Running head: TIME COURSE OF MOTOR GAINS INDUCED BY MUSIC-SUPPORTED THERAPY AFTER STROKE: AN EXPLORATORY CASE STUDY

Interestingly, MST can have a positive impact not only on the motor domain, but also on cognition, mood, and quality of life. In a recent study, chronic patients treated with MST showed a cognitive improvement in attention, speed of processing, and rate of verbal learning (Ripollés et al., 2015). Moreover, MST was found to reduce negative affective symptoms and increase positive affect and quality of life. Similarly, also daily music listening has been found to enhance the recovery of verbal memory and focused attention and prevent negative mood in acute stroke patients. These behavioral gains were linked functionally to enhanced neural efficiency of auditory encoding, as indexed by the mismatch negativity (MNN) response, and structurally to increased grey matter volume in spared prefrontal and limbic regions (Särkämö et al., 2010, 2014). Overall, music has a remarkable ability to elicit positive emotions, motivate and engage patients with the rehabilitation activity, and promote recovery and brain plasticity (Altenmüller \& Schlaug, 2015).

However, some aspects of MST still remain unclear. First, previous studies have only evaluated patients at the beginning and at the end of the treatment. Therefore, the exact time course and the intersession progression of the different motor effects of MST across treatment have not been systematically explored. Second, MST protocols usually are applied in a period of 3 or 4 weeks but the potential benefit of repeating or extending the training has not been studied. Consequently, taking in consideration the first and second aspects, an optimal dose-response has not been established. Thirdly, it is unclear if the motor improvements in chronic stroke patients treated with MST are maintained without treatment over time. Finally, the degree to which the gains observed in playingrelated motor skills transfer to other motor tasks and generalize to better activities of daily living functions, is still largely undetermined.

Here, we present a stroke patient case study with an $\mathrm{ABAB}$ design, which aimed to (i) explore the progression of the rehabilitation of the motor deficits throughout the sessions of a 4-week MST treatment, (ii) examine the effects of a second MST treatment period in the motor and functional 
Running head: TIME COURSE OF MOTOR GAINS INDUCED BY MUSIC-SUPPORTED THERAPY AFTER STROKE: AN EXPLORATORY CASE STUDY

domain, (iii) study the retention of gains during an off-treatment period and (iv) investigate the generalization of gains to activities of daily living. Our hypotheses were that (i) the enhancement of playing-related motor skills and general motor skills induced by the MST would show a different temporal trajectory; (ii) the second MST period would be important for enhancing functional gains; (iii) motor gains would be maintained over time and (iv) transfer or generalization to other motor task would occur at the end of the training.

\section{Participants}

The patient was a 55-year-old right-handed male who suffered an ischemic stroke 18 months prior to his enrollment in the study at the Department of Physical Medicine and Rehabilitation of the [masked hospital], [masked city and country]. The stroke was located in the right anterior choroidal artery, causing lesions in the right internal capsule and thalamus, and was classified as a small vessel occlusion following the TOAST criteria (Adams et al., 1993). Figure 1A shows a structural MRI T1image of the lesion. At the acute stage, the patient presented dysarthria, inferior left facial paresis and hemiplegia in the left upper and lower extremities, with a score of 11 in the National Institute of Health Stroke Scale (NIHSS) that assesses presence and severity of symptoms after stroke (Brott et al., 1989). After being in the stroke unit, the patient received 8 months of a standard neurorehabilitation program in an intensive rehabilitation outpatient facility and was discharged 10 months prior his participation in the study. At the beginning of the study, the patient still presented a slight paresis of the left upper extremity (UE) and mild paresis in the lower left extremity, needing a walking stick (NIHSS score= 3) and affecting the ability of the patient to perform instrumental activities of daily living. In regard to his education and past occupations, the patient studied until the age of 19, completing a vocational training course in mechanics. He worked as a security guard for 28 years but since the stroke the patient has retired due to his medical condition. The patient had not 
Running head: TIME COURSE OF MOTOR GAINS INDUCED BY MUSIC-SUPPORTED THERAPY AFTER STROKE: AN EXPLORATORY CASE STUDY

received any formal music education or musical training and reported to listen to music daily through television, radio and his smartphone, and to dance once a week at home. The styles of music the patient enjoys are jazz, swing, pop and reggae. The patient obtained normal values in music pleasure, with a total score of 68 out of 100 in the Barcelona Music Reward Questionnaire that assesses reward experiences associated with music (Mas-Herrero, Marco-Pallares, Lorenzo-Seva, Zatorre, \& Rodriguez-Fornells, 2013).

In addition, normative data for non-standardized outcome measures was obtained from altogether 15 healthy right-handed and age-matched control subjects (see below).

\section{Experimental design}

A reversal design (ABAB) (Smith, 2012) where no treatment was provided in the $A$ periods and MST was applied in the $B$ periods with repeated assessment across each period was implemented in a chronic stroke patient. The study comprised four 4-week stages (16 weeks in total): an initial baseline period (weeks 1-4), first Music-Supported Therapy treatment period (MST-1, weeks 5-8), a withdrawal period (weeks 9-12) and a second Music-Supported Therapy treatment period (MST-2, weeks 13-16). An extensive assessment of motor function (see below) was performed at the end of each week (from week 1 to 16). In addition, a longitudinal follow-up evaluation was done three months after the end of MST-2 (week 28). Figure 1B illustrates the design of the study. The study was approved by the clinical research ethical committee of [masked name], [masked city and country], and the patient gave written informed consent.

\section{Music-Supported Therapy (MST)}

The treatment periods (MST-1 and MST-2) both consisted on three MST sessions of $1.5 \mathrm{~h}$ per week during four weeks [24 sessions (36 hours) in total]. The central idea in MST is to promote plastic changes in the sensorimotor cortex due to motor skill learning and facilitate the 
Running head: TIME COURSE OF MOTOR GAINS INDUCED BY MUSIC-SUPPORTED THERAPY AFTER STROKE: AN EXPLORATORY CASE STUDY

reestablishment of the audio-motor coupling loop (Rodriguez-Fornells et al., 2012). Patients play musical instruments with the UE and, importantly, the auditory feedback produced by the musical instrument may be used to evaluate on-line motor actions and to influence motor outputs.

In each session, a digital keyboard (CTK-810/WK110, Casio Europe GmbH, Norderstedt, Germany) and an electronic drum set of 8 pads (Roland drum system, TD-6KW, Roland Corporation, Hamamatsu, Japan) were used during 45 min each to train fine and gross movements of the affected UE, respectively. The order in which each instrument was played was counterbalanced across sessions.

For the keyboard training, the instrument was on a table at a distance of $\sim 35 \mathrm{~cm}$ from the edge. The patient was seated in front of the keyboard, with the elbow flexed at 90 and the forearm resting on the table. Only eight consecutive notes were used (C, D, E, F, G, A, B, C') and the hand was positioned in the middle of the octave with a slight extension of the wrist and the fingers resting on the keys. For the drum playing, the patient was seated in a chair without armrests and the drum set was placed at a distance of $\sim 45 \mathrm{~cm}$ with the 8 pads of $20 \mathrm{~cm}$ of diameter around both sides of the body. The pads produced piano sounds (C, D, E, F, G, A, B, C') to maintain the auditory feedback constant during the session. The therapist was seated next to the patient or standing behind on the affected side, providing physical assistance when it was needed and correcting compensatory movements. The exercises consisted of playing simple tone sequences until the patient could learn to play short melodies following a modular regime. Exercises were first shown by the therapist and then repeated by the patient. If the patient succeeded, the difficulty of the sequence was progressively increased. Stickers labeling the keys and the pads with numbers from 1 to 8 were used as a cue to produce sequences. The exercises with the keyboard involved movements of flexion, extension, adduction and abduction of the fingers and thumb. The drum training, aimed to enhance gross motor function, required movements of flexion, adduction and abduction of the shoulder as well as its 
Running head: TIME COURSE OF MOTOR GAINS INDUCED BY MUSIC-SUPPORTED THERAPY AFTER STROKE: AN EXPLORATORY CASE STUDY

internal and external rotation. Movements of flexion and extension of the elbow and wrist were needed to hit the pads. Overall, the training was aimed at increasing the range of movement, coordination and speed.

\section{Motor function assessment}

An extensive evaluation of the motor function was performed at the end of each week using standardized motor tests and 3D movement analysis. In addition, during the treatment periods, the performance of the patient playing an octave with the keyboard was recorded at the end of each session.

Clinical motor tests. To evaluate the level of impairment, the Upper Extremity subtest from the Fugl-Meyer Assessment of Motor Recovery (FMA) (Fugl-Meyer, Jääskö, Leyman, Olsson, \& Steglind, 1975) was administered. Grip strength of both UEs was measured with a dynamometer (ELink System H500, Biometrics Ltd, Newport, United Kingdom) as the mean of three trials. Finger dexterity and gross manual dexterity were assessed with the Nine Hole Pegboard Test (NHPT) (Parker, Wade, \& Langton Hewer, 1986) and the Box and Blocks Test (BBT) (Mathiowetz, Volland, Kashman, \& Weber, 1985), respectively. The unaffected (right) UE was also evaluated with these two tests in order to compare the performance to the affected (left) UE. The overall functioning of the affected UE was evaluated with the Action Research Arm Test (ARAT) (Lyle, 1981). The FMA, grip strength, NHPT, BBT and ARAT were performed each week (weeks 1-16).

Moreover, only at the beginning of the study and at the end of each period (weeks 1, 4, 8, 12, and 16), the Chedoke Arm and Hand Activity Inventory (CAHAI) (Barreca, Stratford, Lambert, Masters, \& Streiner, 2005), which measures the ability of the affected UE to perform bimanual tasks from activities of daily life, was administered. All the tests were performed also at the longitudinal follow-up evaluation (week 28). 
Running head: TIME COURSE OF MOTOR GAINS INDUCED BY MUSIC-SUPPORTED THERAPY AFTER STROKE: AN EXPLORATORY CASE STUDY

3D movement analysis. The movement analysis was performed using an ultrasonic device

(CMS 50, Zebris, Isny, Germany) that recorded the continuous 3D spatial positions of markers attached to the hand of the patient. Three different motor tasks were recorded with both UEs: a finger and a hand tapping task, and a target reaching task (Amengual et al., 2013). A control group of 10 healthy participants (all males, mean age $55.9 \pm 6.4$ ) performed the same evaluation at the beginning of the study.

For the finger and hand tapping task, participants were asked to perform a continuous tapping with the index finger or the whole hand, respectively. Three trials were recorded and the following parameters were obtained per trial: (i) frequency, as the number of tappings per second, as well as, (ii) mean velocity and (iii) smoothness of the movement, as the number of inversions in the velocity per movement segment. The mean of the three trials was accounted for the analysis.

In the target reaching task, participants had to reach a round target of $0.8 \mathrm{~cm}$ of diameter that was placed on a table at a distance of $35 \mathrm{~cm}$ from the patient and height of $10 \mathrm{~cm}$. Eight trials were recorded and the mean of the trials was performed to obtain (i) the time to peak velocity in reaching, (ii) the maximum acceleration in reaching, and (iii) the smoothness of the movement around the target.

Keyboard performance. At the end of each MST session the patient was asked to play an octave (C, D, E, F, G, A, B, C') with the keyboard. This exercise was recorded for the index and middle finger and the MIDI output was obtained. The same task was recorded at baseline for 5 healthy control participants ( 3 females, mean age $55.2 \pm 3.4$ ). The duration of the sequence was calculated as well as the strength used to strike the keys. As the strength was obtained for each individual key press, the mean of the 16 values of the octave ( 8 with the index finger and 8 with the middle finger) was calculated to have a score per sequence and session. 
Running head: TIME COURSE OF MOTOR GAINS INDUCED BY MUSIC-SUPPORTED THERAPY AFTER STROKE: AN EXPLORATORY CASE STUDY

For the clinical standardized motor tests (with exception of the CAHAI), we obtained 16 data points ( 4 per period) and calculated the mean of each period. The Minimal Detectable Change (MDC) or the Minimal Clinically Important Difference (MCID) of each test was added to the mean baseline in order to determine if the subsequent evaluations reached a clinically significant level of gain. The MDC estimates statistically the smallest change in an outcome measure that can be detected beyond the measurement error and represents a noticeable change in ability and similarly, the MCID is the smallest amount of change that is considered important by the patient or clinician.

Due to the high sensitivity of the 3D movement analysis parameters, the mean of each period was computed and compared to the mean of the control group. For the keyboard performance, the mean of the index and middle finger sequences was performed per each session and compared to the performance of the control participants.

\section{Clinical motor tests}

The scores of the patient in all clinical motor tests at different time points are shown in Table 1. Figure 2 illustrates the results for those tests which showed a treatment effect.

Grip Strength. The MCID for the grip strength of the affected (non-dominant) UE is $6.2 \mathrm{Kg}$ (Lang, Edwards, Birkenmeier, \& Dromerick, 2008). For the affected UE, the patient scored 29.7 ( \pm 1.5) $\mathrm{Kg}$ at baseline (Figure 2A). During MST-1 and MST-2, the mean grip strength increased progressively to $33.4( \pm 1.5) \mathrm{Kg}$ and $34.7( \pm 1.6) \mathrm{Kg}$, respectively, but did not quite reach the MCID level (only the second week of MST-2 showed a significant improvement above MCID).

Interestingly, during the withdrawal period, the mean score returned to the baseline levels $(29.5 \pm 2.1$ $\mathrm{Kg}$ ), indicating that MST-1 was not enough to achieve lasting gains. In contrast, at the longitudinal 
Running head: TIME COURSE OF MOTOR GAINS INDUCED BY MUSIC-SUPPORTED THERAPY AFTER STROKE: AN EXPLORATORY CASE STUDY

follow-up (week 28), the grip strength remained at a similar level as in MST-2. For the unaffected

UE, the baseline mean grip strength of the patient $(44.5 \mathrm{Kg} \pm 1.6 \mathrm{Kg})$ was already within normal limits for his age (45 Kg) (Massy-Westropp, Gill, Taylor, Bohannon, \& Hill, 2011) and remained relatively same during the follow-up.

Box and Blocks Test. In the BBT, the mean score of the patient for the affected UE at baseline was $31.2( \pm 2.3)$ blocks per minute and the MDC is 5.5 blocks per minute (Chen, Chen, Hsueh, Huang, \& Hsieh, 2009) (Figure 2B). Therefore, a score above 36.7 was considered as clinically relevant. During MST-1, there was a slight mean increase to $34.5( \pm 2.5)$ blocks per minute, exceeding the MDC on the last week (38 blocks per minute). At the withdrawal phase, the patient remained stable in this test, maintaining the gains, with a mean score of $37.2( \pm 0.9)$. During MST-2, the patient continued improving, and the mean performance was clearly above the MCD (40.5 \pm 2.3$)$. Importantly, this significant gain was maintained in the follow-up evaluation at week 28 (39 blocks per minute). Interestingly, the unaffected UE exhibited a similar pattern, with progressive improvement towards the end of MST-1, plateauing at withdrawal, and further improvement during MST-2, indicating a positive transfer effect of the MST for gross motor speed of the unaffected UE.

Action Research Arm Test. In the ARAT test the patient had a relatively high mean score already at baseline (52 \pm 1.4$)$. However, during the MST-1, withdrawal, and MST-2 periods, the patient showed progressive gains in the mean score, which reached MCID (5.7 points above baseline (van der Lee, Beckerman, Lankhorst, \& Bouter, 2001) at MST-2 (Figure 2C). In the follow-up evaluation (week 28), the improvements seen during the MST-2 were, however, not maintained.

\section{Chedoke Arm and Hand Activity Inventory. The CAHAI was administered only at the} beginning and at the end of each period. The results of this test are presented in Figure 2D. For the baseline period, we calculated the mean, which was $70.5( \pm 3.5)$. The MDC is 6.3 points (Barreca et al., 2005), which was achieved already after MST-1 (79 points). This relevant level of gain was 
Running head: TIME COURSE OF MOTOR GAINS INDUCED BY MUSIC-SUPPORTED THERAPY AFTER STROKE: AN EXPLORATORY CASE STUDY

stable over the withdrawal period and, importantly, the patient still continued improving during MST-2 (80 points). At the follow-up evaluation the gains were also maintained.

Fugl-Meyer Assessment of Motor Recovery and Nine Hole Pegboard Test. For the FMA and NHPT (Wagner, Rhodes, \& Patten, 2008; Chen et al., 2009), the MDC was not achieved in any of the evaluations although the patient progressively obtained better scores in the NHPT during the treatment periods.

In summary, these results indicated that major clinical motor gains were noticeable at the end of MST-1 and during MST-2.

\section{D movement analysis.}

Table 2 shows the scores for the 3D movement analysis where the mean of each period was calculated. The mean velocity of the affected UE in both finger and hand tapping tasks improved during both MST-1 and MST-2, even rising above the mean score of the controls for the hand tapping task (701.6 $\pm 65.5 \mathrm{~mm} / \mathrm{s})$ (Figure 3A, 3B). For the unaffected UE, the mean velocity of the hand tapping increased during both MST-1 and MST-2 while the mean velocity of the finger tapping showed some increase only during MST-2. The smoothness of the finger tapping for both UEs was comparable to the controls across the follow-up, showing no clear changes. In the hand tapping task, the smoothness of the affected UE also remained relatively stable during MST-1 and MST-2, but showed a decline in the withdrawal period. The frequency of both finger and hand tapping tasks for both UEs was smaller than the frequency that controls exhibited and did not show any improvement across time.

In the target reaching task (Figure 3C), the patient's performance with the affected UE became faster especially during MST-2, as indicated by decreased time to achieve maximum velocity of movement $(144.4 \pm 19.6 \mathrm{~ms})$. The time-to-peak velocity of the unaffected UE was not within the 
Running head: TIME COURSE OF MOTOR GAINS INDUCED BY MUSIC-SUPPORTED THERAPY AFTER STROKE: AN EXPLORATORY CASE STUDY normal range of controls in any time point. Although the maximum acceleration scores for both UEs were within normal range scores, there was a slight increase in MST-2 $\left(65.5 \pm 19.2 \mathrm{~mm} / \mathrm{s}^{2}\right)$ for affected UE. Also, the smoothness of the movements when approaching the target improved during the withdrawal and MST-2 periods, reaching scores that were below the mean of controls for both UEs.

In summary, the results from the 3D movement analysis indicated that, during the treatment periods, the velocity in the finger and hand tapping task improved. In contrast, the parameters in the reaching task only improved during the second treatment period (MST-2).

\section{Keyboard performance.}

The sequence duration, obtained as the mean of the two sequences (with the index and middle finger), decreased steadily across the sessions during MST-1 (Figure 4A). During MST-2, the gains in this parameter were maintained, but no further progress was observed. Also the variance of performance within each session decreased towards the end of MST-1 and remained smaller during MST-2. However, the performance of the patient remained slower than that of the controls.

A similar pattern of results was observed for the amount of pressure applied when pressing the keys of the keyboard. During the first half of MST-1, key pressure was smaller and also more variable than in controls (Figure 4B). However, from session eight of MST-1, the performance of the patient started to show more power and stability, becoming within normal range compared to controls. These gains were again maintained during MST-2.

In summary, the results from the analysis of keyboard performance indicated that the main gains in terms of speed and strength where seen during MST-1. 
Running head: TIME COURSE OF MOTOR GAINS INDUCED BY MUSIC-SUPPORTED THERAPY

AFTER STROKE: AN EXPLORATORY CASE STUDY

\section{Discussion}

This study examined the progression of the motor and functional gains of a chronic stroke patient treated with MST in a case-study with an ABAB design. Three different types of evaluation were performed: (i) the clinical motor test assessed the functional use of the hand in other tasks not directly related to the treatment and in activities of daily living, (ii) the $3 \mathrm{D}$ movement analysis evaluated the kinematics properties of movements and (iii) the keyboard task assessed the motor performance in a task-specific to the training.

The patient showed significant improvements in the clinical motor domain at the end of MST1 (BBT and CAHAI), and during MST-2 (grip strength, BBT, ARAT, and CAHAI). Some of these gains were maintained over time in the follow-up evaluation performed 3 months after MST- 2 .

Moreover, the velocity of a finger and hand tapping task increased during MST-1 and MST-2, whereas the kinematic properties of a reaching task improved only in MST-2. Importantly, gains in a keyboard task were only seen during the first sessions of MST-1. These results are in agreement with previous research validating MST in subacute and chronic stroke patients where motor improvements were also observed. For instance, similar results in the BBT and ARAT scores have been reported in stroke patients who received MST (Grau-Sánchez et al., 2013; Ripollés et al., 2015). Moreover, improvements in a finger and hand tapping task have been also found after the application of MST (Amengual et al., 2013; Schneider et al., 2007).

MST is a task-specific training, aimed to elicit similar processes as those occurring during and after motor skill learning, where movements become more accurate and quick with practice (Dayan \& Cohen, 2011). It is known that the acquisition of a new motor skill develops fast at the beginning of the training (Censor, Sagi, \& Cohen, 2012). In this sense, major improvements where seen during the first sessions of MST-1 in the keyboard task. The patient pressed the keys with more strength and needed less time to play an octave. Similarly, the finger and hand tapping velocity increased during 
Running head: TIME COURSE OF MOTOR GAINS INDUCED BY MUSIC-SUPPORTED THERAPY AFTER STROKE: AN EXPLORATORY CASE STUDY

MST-1. Importantly, these movements are required for the keyboard and drum pads playing.

Therefore, both the keyboard task and the finger and hand tapping tasks evidenced fast acquisition and task-specific learning. Only at the end of MST-1 improvements were observed at a functional level as the patient obtained significant better scores in the BBT and CAHAI. The patient also improved during MST-1 in other tests such as the grip strength, the ARAT and the NHPT although these gains were not significant.

In the withdrawal period this patient did not receive any kind of treatment, which can be compared to an offline period in the process of motor skill learning (Dayan \& Cohen, 2011). It has been reported that in the absence of practice there is stabilization and consolidation of motor memory traces, where new motor memories could become more robust (Robertson, Pascual-Leone, \& Miall, 2004). During this period, the scores for the BBT and CAHAI remained stable. The fact that these gains were maintained over time may evidence long-term retention. It has been discussed that improvements can take place also during offline periods (Censor et al., 2012). This was the case for the ARAT evaluation, where the patient improved slightly during the withdrawal period. However, the gains observed in the grip strength disappeared.

The additional treatment provided during MST-2 may be considered as a period where memory reactivation of motor traces occurs and it is further modified with practice. In this period, the patient did not show any improvement in the keyboard task. The key pressure remained at the same level that the patient reached in MST-1, being within the normative values of controls. The duration of the octave also remained as in MST-1 although did not reach similar times compared to controls. On the other hand, the patient reached a significant level of gain in the BBT in and CAHAI during MST-2, and in some of the evaluations of this period in the ARAT and grip strength. Besides, the mean velocity of the finger and hand tapping tasks as well as the time-to-peak velocity, maximum acceleration and smoothness of the reaching task improved during MST-2. Overall, major gains in 
Running head: TIME COURSE OF MOTOR GAINS INDUCED BY MUSIC-SUPPORTED THERAPY AFTER STROKE: AN EXPLORATORY CASE STUDY

the clinical motor tests were seen in MST-2, meaning that generalization to other tasks occurred mostly at this period. Most of the clinical motor gains were maintained in the follow-up evaluation, which may reflect improved long-term retention.

With regard to the aims of the study, the interim conclusions are that (i) fast acquisition within the same task occurs during the first MST sessions, but generalization to other motor tasks is prominent only at the end of the MST training; (ii) the second MST training does not have effects on the musical instrument performance but it may be important for the generalization of improvements to other tasks and long-term retention; (iii) during the withdrawal period gains can be maintained, improved or lost; and (iv) generalization of gains to activities of daily living occurs during the second treatment period.

Indeed, one of the important findings of the present study is the improvement seen in the CAHAI. This test evaluates the functional ability of the affected UE in performing bimanual tasks from activities of daily living. For instance, the patient is asked to make a phone call, pour a glass of water, or put toothpaste on a toothbrush, among others. Previous literature on MST had never evaluated this domain and importantly, this study points out that the motor improvements due to MST may be transferred to activities of daily living. This may be crucial as the ultimate goal in stroke motor rehabilitation is to reduce the limitations in activities of daily living, which have an impact in the participation and the quality of life of patients (Langhorne et al., 2011).

The FMA and the NHPT were the only clinical motor tests that did not show any significant improvement in any of the evaluations. For the NHPT, the patient progressively scored better across the different evaluations but the change was not significant. The MDC for this test, which is 32 seconds, was established in a sample of acute stroke patients who usually present a major room for improvement (Turton \& Pomeroy, 2002). One possible explanation for the lack of results in this test may be that the MDC is difficult to achieve in chronic stroke patients. Moreover, previous studies in 
Running head: TIME COURSE OF MOTOR GAINS INDUCED BY MUSIC-SUPPORTED THERAPY AFTER STROKE: AN EXPLORATORY CASE STUDY

chronic stroke patients treated with MST did not find any improvement in this test (Amengual et al., 2013; Grau-Sánchez et al., 2013; Ripollés et al., 2015). Thus, it could be argued that MST does not promote gains that can be observed with this test in chronic stroke patients.

With respect to the training protocol, the study from Schneider and colleagues had 15 sessions whereas the studies in chronic patients contained 20 sessions (Rodriguez-Fornells et al., 2012; Schneider et al., 2007). In these studies, the sessions were administered daily during 30 minutes. In contrast, in the present study, the patient received only 3 sessions per week which made the training more distributed with longer rest periods between sessions. Moreover, the sessions lasted $1.5 \mathrm{~h}$ and thus, were more intense. This modification was intended to facilitate a major degree of improvement as this depends on the amount of practice (Lage et al., 2015). Besides, two instruments were used in each session, where the first half of the session was dedicated to play one instrument and the last part to play the other one. This contextual interference is thought to be positive for the training as it has been described that better performance is achieved if more than a single task is practiced alone (Krakauer, 2006; Pauwels, Swinnen, \& Beets, 2014). A future modification of the protocol can be to involve both extremities in the activity where the unaffected upper extremity can serve as an intrasubject control. Bilateral arm training has emerged in the past years based on the idea that the majority of everyday tasks and activities require the use of both extremities and that rehabilitation programs with more ecological approaches may be more effective in improving the autonomy of patients (McCombe Waller \& Whitall, 2008). Different studies have demonstrated the effectiveness of bilateral training with sensory feedback (Stewart, Cauraugh, \& Summers, 2006) and specifically with rhythmic auditory cueing (Whitall, McCombe Waller, Silver, \& Macko, 2000). Future studies should investigate the effectiveness of applying MST as bilateral arm training.

As mentioned, MST has been already evaluated in previous works using experimental groups designs where two groups are compared at pre- and post- intervention (Altenmüller et al., 2009; Amengual et al., 2013; Ripollés et al., 2015; Rodriguez-Fornells et al., 2012). Given the existing 
Running head: TIME COURSE OF MOTOR GAINS INDUCED BY MUSIC-SUPPORTED THERAPY AFTER STROKE: AN EXPLORATORY CASE STUDY

evidence about its benefits, the aim of the present study was to explore the progression of motor recovery in MST using single-case methodology. This type of methodology, which is frequently used in psychology, rehabilitation or education, is more sensitive to individual differences and the participant serves as his/her own control. However, single-case designs are subject to several limitations, such as order effects or blinding of the patient and therapist, which is difficult in behavioral interventions. In the case of stroke rehabilitation, we dealt with irreversibility and carry-over effects, not having a clear reversion in the withdrawal for most measures. However, this is in favor of the intervention tested, since improvements are maintained over time and do not disappear when the treatment is removed. Although previous studies have included both hemorrhagic and ischemic stroke patients in their samples, the description of the pattern of progression of this study is from a patient with an ischemic stroke. Future research should investigate whether hemorrhagic stroke patients treated with MST show a similar time course of motor gains.

As a summary, this study evaluated the progression of the motor and functional improvements in a chronic stroke patient treated with MST. Given the exploratory nature of the study, its results cannot be generalized but may provide a deeper understanding of the motor progression in MST and raise new questions with regard to the MST protocol. Future studies are needed to further investigate how these variations in the MST protocol as well as the offline periods benefit the recovery of motor deficits. 
Running head: TIME COURSE OF MOTOR GAINS INDUCED BY MUSIC-SUPPORTED THERAPY

AFTER STROKE: AN EXPLORATORY CASE STUDY

461

462

463

464

465

466

467

468

469

470

471

472

473

474

475

476

477

478

479

480

481

482

\section{References}

Adams, H. P., Bendixen, B. H., Kappelle, L. J., Biller, J., Love, B. B., Gordon, D. L., \& Marsh, E. E. (1993). Classification of subtype of acute ischemic stroke. Definitions for use in a multicenter clinical trial. TOAST. Trial of Org 10172 in Acute Stroke Treatment. Stroke; a Journal of Cerebral Circulation, 24(1), 35-41.

Altenmüller, E., Marco-Pallares, J., Münte, T. F., \& Schneider, S. (2009). Neural reorganization underlies improvement in stroke-induced motor dysfunction by music-supported therapy. Annals of the New York Academy of Sciences, 1169, 395-405. doi:10.1111/j.17496632.2009.04580.x

Altenmüller, E., \& Schlaug, G. (2015). Apollo's gift: new aspects of neurologic music therapy. Progress in Brain Research, 217, 237-52. doi:10.1016/bs.pbr.2014.11.029

Amengual, J. L., Rojo, N., Veciana de las Heras, M., Marco-Pallarés, J., Grau-Sánchez, J., Schneider, S., ... Rodríguez-Fornells, A. (2013). Sensorimotor Plasticity after Music-Supported Therapy in Chronic Stroke Patients Revealed by Transcranial Magnetic Stimulation. PLoS ONE, 8(4), 1-10. doi:10.1371/journal.pone.0061883

Bangert, M., Peschel, T., Schlaug, G., Rotte, M., Drescher, D., Hinrichs, H., ... Altenmüller, E. (2006). Shared networks for auditory and motor processing in professional pianists: Evidence from fMRI conjunction. NeuroImage, 30(3), 917-926. doi:10.1016/j.neuroimage.2005.10.044

Barreca, S. R., Stratford, P. W., Lambert, C. L., Masters, L. M., \& Streiner, D. L. (2005). Test-retest reliability, validity, and sensitivity of the Chedoke arm and hand activity inventory: a new measure of upper-limb function for survivors of stroke. Archives of Physical Medicine and Rehabilitation, 86(8), 1616-22. doi:10.1016/j.apmr.2005.03.017 
Running head: TIME COURSE OF MOTOR GAINS INDUCED BY MUSIC-SUPPORTED THERAPY AFTER STROKE: AN EXPLORATORY CASE STUDY

Baumann, S., Koeneke, S., Meyer, M., Lutz, K., \& Jäncke, L. (2005). A network for sensory-motor integration: what happens in the auditory cortex during piano playing without acoustic feedback? Annals of the New York Academy of Sciences, 1060, 186-8. doi:10.1196/annals.1360.038

Brott, T., Jr, H. P. A., Olinger, C. P., Marler, J. R., Barsan, W. G., Biller, J., ... Walker, M. (1989). Measurements of Acute Cerebral Infarction :, 1, 864-871.

Carmichael, S. T., \& Krakauer, J. W. (2013). The promise of neuro-recovery after stroke: Introduction. Stroke, 44(SUPPL. 1). doi:10.1161/STROKEAHA.111.000373

Censor, N., Sagi, D., \& Cohen, L. G. (2012). Common mechanisms of human perceptual and motor learning. Nature Reviews. Neuroscience, 13(September), 658-64. doi:10.1038/nrn3315

Chen, H.-M., Chen, C., Hsueh, I.-P., Huang, S., \& Hsieh, C. (2009). Test-Retest Reproducibility and Smallest Real With Stroke. Neurorehabilitation and Neural Repair, 23(17), 435-440. doi:10.1177/1545968308331146

Cramer, S. C., Sur, M., Dobkin, B. H., O’Brien, C., Sanger, T. D., Trojanowski, J. Q., ... Vinogradov, S. (2011). Harnessing neuroplasticity for clinical applications. Brain, 134(6), 1591-1609. doi:10.1093/brain/awr039

Dayan, E., \& Cohen, L. G. (2011). Neuroplasticity subserving motor skill learning. Neuron, 72(3), 443-454. doi:10.1016/j.neuron.2011.10.008

Fugl-Meyer, A. R., Jääskö, L., Leyman, I., Olsson, S., \& Steglind, S. (1975). The post-stroke hemiplegic patient. 1. a method for evaluation of physical performance. Scandinavian Journal of Rehabilitation Medicine, 7(1), 13-31.

Grau-Sánchez, J., Amengual, J. L., Rojo, N., Veciana de Las Heras, M., Montero, J., Rubio, F., ... 
Running head: TIME COURSE OF MOTOR GAINS INDUCED BY MUSIC-SUPPORTED THERAPY AFTER STROKE: AN EXPLORATORY CASE STUDY

505

506

507

508

509

510

511

512

513

514

515

516

517

518

519

520

521

522

523

524

525

526

Rodríguez-Fornells, A. (2013). Plasticity in the sensorimotor cortex induced by Musicsupported therapy in stroke patients: a TMS study. Frontiers in Human Neuroscience, 7(September), 494. doi:10.3389/fnhum.2013.00494

Krakauer, J. W. (2006). Motor learning: its relevance to stroke recovery and neurorehabilitation. Current Opinion in Neurology, 19(1), 84-90. doi:10.1097/01.wco.0000200544.29915.cc

Lage, G. M., Ugrinowitsch, H., Apolinário-Souza, T., Vieira, M. M., Albuquerque, M. R., \& Benda, R. N. (2015). Repetition and variation in motor practice: A review of neural correlates. Neuroscience and Biobehavioral Reviews, 57, 132-41. doi:10.1016/j.neubiorev.2015.08.012

Lang, C. E., Edwards, D. F., Birkenmeier, R. L., \& Dromerick, A. W. (2008). Estimating minimal clinically important differences of upper-extremity measures early after stroke. Archives of Physical Medicine and Rehabilitation, 89(9), 1693-700. doi:10.1016/j.apmr.2008.02.022

Langhorne, P., Bernhardt, J., \& Kwakkel, G. (2011). Stroke rehabilitation. The Lancet, 377(9778), 1693-1702. doi:10.1016/S0140-6736(11)60325-5

Lyle, R. C. (1981). A performance test for assessment of upper limb function in physical rehabilitation treatment and research. International Journal of Rehabilitation Research. Internationale Zeitschrift Für Rehabilitationsforschung. Revue Internationale de Recherches de Réadaptation, 4(4), 483-92.

Mas-Herrero, E., Marco-Pallares, J., Lorenzo-Seva, U., Zatorre, R. J., \& Rodriguez-Fornells, A. (2013). Individual Differences in Music Reward Experiences. Music Perception: An Interdisciplinary Journal, 31(2).

Massy-Westropp, N. M., Gill, T. K., Taylor, A. W., Bohannon, R. W., \& Hill, C. L. (2011). Hand Grip Strength: age and gender stratified normative data in a population-based study. $B M C$ 
Running head: TIME COURSE OF MOTOR GAINS INDUCED BY MUSIC-SUPPORTED THERAPY

AFTER STROKE: AN EXPLORATORY CASE STUDY

Research Notes, 4, 127. doi:10.1186/1756-0500-4-127

528

529

530

531

532

533

534

535

536

537

538

539

540

541

Mathiowetz, V., Volland, G., Kashman, N., \& Weber, K. (1985). Adult norms for the Box and Block Test of manual dexterity. The American Journal of Occupational Therapy: Official Publication of the American Occupational Therapy Association, 39(6), 386-91.

McCombe Waller, S., \& Whitall, J. (2008). Bilateral arm training: why and who benefits? NeuroRehabilitation, 23(1), 29-41.

Parker, V. M., Wade, D. T., \& Langton Hewer, R. (1986). Loss of arm function after stroke: measurement, frequency, and recovery. International Rehabilitation Medicine, 8(2), 69-73.

Pauwels, L., Swinnen, S. P., \& Beets, I. A. M. (2014). Contextual interference in complex bimanual skill learning leads to better skill persistence. PloS One, 9(6), e100906. doi:10.1371/journal.pone.0100906

Pomeroy, V., Aglioti, S. M., Mark, V. W., McFarland, D., Stinear, C., Wolf, S. L., ... Fitzpatrick, S. M. (2011). Neurological principles and rehabilitation of action disorders: rehabilitation interventions. Neurorehabilitation and Neural Repair, 25(5 Suppl), 33S-43S. doi: $10.1177 / 1545968311410942$

Rathore, S. S., Hinn, A. R., Cooper, L. S., Tyroler, H. A., \& Rosamond, W. D. (2002). Characterization of incident stroke signs and symptoms findings from the atherosclerosis risk in communities study. Stroke, 33(11), 2718-2721. doi:10.1161/01.STR.0000035286.87503.31

Ripollés, P., Rojo, N., Grau-Sánchez, J., Amengual, J. L., Càmara, E., Marco-Pallarés, J., ... Rodríguez-Fornells, A. (2015). Music supported therapy promotes motor plasticity in individuals with chronic stroke. Brain Imaging and Behavior, 1-19. doi:10.1007/s11682-0159498-x 
Running head: TIME COURSE OF MOTOR GAINS INDUCED BY MUSIC-SUPPORTED THERAPY AFTER STROKE: AN EXPLORATORY CASE STUDY

Robertson, E. M., Pascual-Leone, A., \& Miall, R. C. (2004). Current concepts in procedural consolidation. Nature Reviews. Neuroscience, 5(7), 576-82. doi:10.1038/nrn1426

Rodriguez-Fornells, A., Rojo, N., Amengual, J. L., Ripollés, P., Altenmüller, E., \& Münte, T. F. (2012). The involvement of audio-motor coupling in the music-supported therapy applied to stroke patients. Annals of the New York Academy of Sciences, 1252(1), 282-293. doi:10.1111/j.1749-6632.2011.06425.x

Rojo, N., Amengual, J., Juncadella, M., Rubio, F., Camara, E., Marco-Pallares, J., ... RodriguezFornells, A. (2011). Music-supported therapy induces plasticity in the sensorimotor cortex in chronic stroke: a single-case study using multimodal imaging (fMRI-TMS). Brain Injury: [BI], 25(7-8), 787-793. doi:10.3109/02699052.2011.576305

Särkämö, T., Pihko, E., Laitinen, S., Forsblom, A., Soinila, S., Mikkonen, M., ... Tervaniemi, M. (2010). Music and speech listening enhance the recovery of early sensory processing after stroke. Journal of Cognitive Neuroscience, 22(12), 2716-27. doi:10.1162/jocn.2009.21376

Särkämö, T., Ripollés, P., Vepsäläinen, H., Autti, T., Silvennoinen, H. M., Salli, E., ... RodríguezFornells, A. (2014). Structural changes induced by daily music listening in the recovering brain after middle cerebral artery stroke: a voxel-based morphometry study. Frontiers in Human Neuroscience, 8(April), 245. doi:10.3389/fnhum.2014.00245

Schlaug, G. (2015). Musicians and music making as a model for the study of brain plasticity. Progress in Brain Research, 217, 37-55. doi:10.1016/bs.pbr.2014.11.020

Schneider, S., Schönle, P. W., Altenmüller, E., \& Münte, T. F. (2007). Using musical instruments to improve motor skill recovery following a stroke. Journal of Neurology, 254(10), 1339-1346. doi:10.1007/s00415-006-0523-2 
Running head: TIME COURSE OF MOTOR GAINS INDUCED BY MUSIC-SUPPORTED THERAPY AFTER STROKE: AN EXPLORATORY CASE STUDY

Smith, J. D. (2012). Single-case experimental designs: a systematic review of published research and current standards. Psychological Methods, 17(4), 510-50. doi:10.1037/a0029312

Stewart, K. C., Cauraugh, J. H., \& Summers, J. J. (2006). Bilateral movement training and stroke rehabilitation: a systematic review and meta-analysis. Journal of the Neurological Sciences, 244(1-2), 89-95. doi:10.1016/j.jns.2006.01.005

Timmermans, A. A. A., Spooren, A. I. F., Kingma, H., \& Seelen, H. A. M. Influence of task-oriented training content on skilled arm-hand performance in stroke: a systematic review. Neurorehabilitation and Neural Repair, 24(9), 858-70. doi:10.1177/1545968310368963

Turton, A., \& Pomeroy, V. (2002). When should upper limb function be trained after stroke? Evidence for and against early intervention. NeuroRehabilitation, 17(3), 215-24.

van der Lee, J. H., Beckerman, H., Lankhorst, G. J., \& Bouter, L. M. (2001). The responsiveness of the Action Research Arm test and the Fugl-Meyer Assessment scale in chronic stroke patients. Journal of Rehabilitation Medicine, 33(3), 110-3.

Visser, M. M., Heijenbrok-Kal, M. H., Spijker, A. V., Oostra, K. M., Busschbach, J. J., \& Ribbers, G. M. (2015). Coping, problem solving, depression, and health-related quality of life in patients receiving outpatient stroke rehabilitation. Archives of Physical Medicine and Rehabilitation, 96(8), 1492-8. doi:10.1016/j.apmr.2015.04.007

Wagner, J. M., Rhodes, J. A., \& Patten, C. (2008). Reproducibility and minimal detectable change of three-dimensional kinematic analysis of reaching tasks in people with hemiparesis after stroke. Physical Therapy, 88(5), 652-63. doi:10.2522/ptj.20070255

Whitall, J., McCombe Waller, S., Silver, K. H., \& Macko, R. F. (2000). Repetitive bilateral arm training with rhythmic auditory cueing improves motor function in chronic hemiparetic stroke. 
Running head: TIME COURSE OF MOTOR GAINS INDUCED BY MUSIC-SUPPORTED THERAPY AFTER STROKE: AN EXPLORATORY CASE STUDY

Stroke; a Journal of Cerebral Circulation, 31(10), 2390-5.

594 Zatorre, R. J., Chen, J. L., \& Penhune, V. B. (2007). When the brain plays music: auditory-motor

595 interactions in music perception and production. Nature Reviews. Neuroscience, 8(7), 547-558.

596 doi:10.1038/nrn2152

597 


\section{Running head: TIME COURSE OF MOTOR GAINS INDUCED BY MUSIC-SUPPORTED THERAPY AFTER STROKE: AN EXPLORATORY CASE STUDY}

598

599

600

601

602

603

604

605

606

607

Table 1. Results of the clinical motor tests. The results for the clinical motor test are presented by each upper extremity (Affected, Unaffected), period (Baseline, MST-1, Withdrawal, and MST-2) and evaluation (weeks from 1 to 16 and follow-up at week 28). The mean and the standard deviation (SD) are calculated by period. The Minimal Detectable Change (MDC) or Minimal Clinically Important Difference (MCID) of each test was added to the mean baseline. The maximum score for the Fug-Meyer is 66 . The grip strength is expressed in Kg. The Nine Hole Pegboard Test is reported as the seconds needed by the patient to perform the task. For this test, it is not possible to subtract the MDC (32.8 seconds) from the baseline as the score does not make sense for the task. Instead, the normative values are presented. The Box and Blocks Test accounts the number of cubes that the patient is able to pass from one box to another in one minute. The maximum score of the ARAT is 57 and 91 for the Chedoke. $\mathrm{W}=$ week; ARAT = Action Research Arm Test.

\begin{tabular}{|c|c|c|c|c|c|c|c|c|c|}
\hline \multicolumn{10}{|c|}{ CLINICAL MOTOR TESTS RESULTS } \\
\hline & \multirow{2}{*}{$\begin{array}{l}\text { Fugl- } \\
\text { Meyer }\end{array}$} & \multicolumn{2}{|c|}{ Grip strength } & \multicolumn{2}{|c|}{$\begin{array}{c}\text { Nine Hole } \\
\text { Pegboard Test }\end{array}$} & \multicolumn{2}{|c|}{ Box and Blocks Test } & \multirow[t]{2}{*}{ ARAT } & \multirow[t]{2}{*}{ Chedoke } \\
\hline & & Affected & Unaffected & Affected & Unaffected & Affected & Unaffected & & \\
\hline \multicolumn{10}{|l|}{ Baseline } \\
\hline $\mathrm{W} 1$ & 62 & 28.7 & 45.6 & 40 & 27 & 33 & 49 & 52 & 73 \\
\hline W2 & 58 & 30.6 & 45.7 & 47 & 23 & 31 & 46 & 54 & \\
\hline W3 & 62 & 31.4 & 42.2 & 45 & 26 & 33 & 48 & 51 & \\
\hline W4 & 60 & 28.1 & 44.5 & 50 & 27 & 28 & 45 & 51 & 68 \\
\hline Mean & 60.5 & 29.7 & 44.5 & 45.5 & 25.7 & 31.2 & 47 & 52 & 70.5 \\
\hline SD & 1.9 & 1.5 & 1.6 & 4.2 & 1.8 & 2.3 & 1.8 & 1.4 & 3.5 \\
\hline$M C I D / M D C$ & 65.7 & 35.9 & 50.7 & 19.8 & 18.9 & 36.7 & 52.5 & 57 & 76.8 \\
\hline \multicolumn{10}{|l|}{$M S T-1$} \\
\hline W5 & 62 & 33.5 & 47.6 & 44 & 23 & 32 & 45 & 51 & \\
\hline W6 & 63 & 34.9 & 50.3 & 41 & 22 & 34 & 46 & 55 & \\
\hline W7 & 64 & 34.2 & 48.6 & 38 & 24 & 34 & 49 & 53 & \\
\hline W8 & 63 & 31.3 & 43.5 & 39 & 23 & 38 & 54 & 55 & 79 \\
\hline Mean & 63 & 33.4 & 47.5 & 40.5 & 23 & 34.5 & 48.5 & 53.5 & \\
\hline $\mathrm{SD}$ & 0.8 & 1.5 & 2.8 & 2.6 & 0.8 & 2.5 & 4 & 1.9 & \\
\hline \multicolumn{10}{|l|}{ Withdrawal } \\
\hline W9 & 62 & 32.6 & 45.3 & 41 & 21 & 37 & 56 & 52 & \\
\hline W10 & 62 & 27.9 & 45.2 & 41 & 24 & 38 & 55 & 56 & \\
\hline W11 & 61 & 29.6 & 47.5 & 39 & 24 & 38 & 57 & 57 & \\
\hline W12 & 62 & 28 & 43.1 & 41 & 22 & 36 & 56 & 56 & 78 \\
\hline Mean & 61.7 & 29.5 & 45.2 & 40.5 & 22.7 & 37.2 & 56 & 55.2 & \\
\hline $\mathrm{SD}$ & 0.5 & 2.1 & 1.8 & 1 & 1.5 & 0.9 & 0.8 & 2.2 & \\
\hline \multicolumn{10}{|l|}{$M S T-2$} \\
\hline W13 & 63 & 33.3 & 45.8 & 38 & 23 & 41 & 62 & 57 & \\
\hline W14 & 62 & 36.7 & 45.5 & 35 & 19 & 42 & 60 & 56 & \\
\hline W15 & 62 & 33.4 & 48.9 & 37 & 23 & 37 & 56 & 56 & \\
\hline W16 & 63 & 35.4 & 49.5 & 39 & 22 & 42 & 64 & 57 & 82 \\
\hline Mean & 62.5 & 34.7 & 47.4 & 37.2 & 21.7 & 40.5 & 60.5 & 56.5 & \\
\hline $\mathrm{SD}$ & 0.5 & 1.6 & 2 & 1.7 & 1.8 & 2.3 & 3.4 & 0.5 & \\
\hline \multicolumn{10}{|l|}{ Follow-up } \\
\hline W28 & 64 & 32.4 & 47.8 & 46 & 20 & 39 & 59 & 55 & 80 \\
\hline
\end{tabular}




\section{Running head: TIME COURSE OF MOTOR GAINS INDUCED BY MUSIC-SUPPORTED THERAPY AFTER STROKE: AN EXPLORATORY CASE STUDY}

Table 2. Results of the 3D movement analysis. The mean and the standard deviation (SD) for the

finger and hand tapping; and reaching tasks are presented by each upper extremity (affected,

The frequency is expressed in $\mathrm{Hz}$, the mean velocity in $\mathrm{mm} / \mathrm{s}$, the time to peak velocity in $\mathrm{ms}$ and the segment and typically is expected to be 1 .

\begin{tabular}{|c|c|c|c|c|c|c|}
\hline \multicolumn{7}{|c|}{ 3D MOVEMENT ANALYSIS RESULTS } \\
\hline & Baseline & MST-1 & Withdrawal & MST-2 & Follow-up & Controls \\
\hline \multicolumn{7}{|l|}{ Finger tapping } \\
\hline Frequency Affected & $1.5(0.1)$ & $2(0)$ & $1.8(0.2)$ & $2.1(0.1)$ & 1.8 & $4.3(1.7)$ \\
\hline Frequency Unaffected & $2.8(0.8)$ & $2.1(0.3)$ & $1.8(0.1)$ & $2.2(0.2)$ & 2 & $4.4(1)$ \\
\hline Mean Velocity Affected & $138.5(16.1)$ & $155.1(16.3)$ & $164.1(17.5)$ & $191.1(16.2)$ & 181 & $222.6(67.7)$ \\
\hline Mean Velocity Unaffected & $189.8(39)$ & $190.7(21.3)$ & $188.2(8.9)$ & $217.8(15.1)$ & 232.5 & $195.3(63.6)$ \\
\hline Smoothness Affected & $1(0)$ & $1(0)$ & $1(0)$ & $1(0)$ & 1 & $1(0)$ \\
\hline Smoothness Unaffected & $1(0)$ & $1.1(0.1)$ & $1(0)$ & $1(0)$ & 1 & $1(0)$ \\
\hline \multicolumn{7}{|l|}{ Hand tapping } \\
\hline Frequency Affected & $1.6(0.1)$ & $1.8(0.1)$ & $1.9(0.1)$ & $2(0.1)$ & 2 & $3.7(1.3)$ \\
\hline Frequency Unaffected & $1.8(0.1)$ & $2(0.1)$ & $1.8(0)$ & $2.1(0.2)$ & 2 & $3.9(1.7)$ \\
\hline Mean Velocity Affected & $395.2(73.3)$ & $552.8(73.6)$ & $620.9(50.2)$ & $701.6(65.5)$ & 640 & $529(229.3)$ \\
\hline Mean Velocity Unaffected & $458.2(61.1)$ & $722.5(92.2)$ & $693.1(59.8)$ & $810.5(92.3)$ & 753.5 & $418.3(149.4)$ \\
\hline Smoothness Affected & $1(0)$ & $1.1(0.1)$ & $1.4(0.1)$ & $1.1(0)$ & 1.3 & $1(0.1)$ \\
\hline Smoothness Unaffected & $1(0)$ & $1(0.1)$ & $1(0)$ & $1.1(0.1)$ & 1 & $1(0)$ \\
\hline \multicolumn{7}{|l|}{ Target reaching } \\
\hline Time to peak velocity Affected & $190(36.1)$ & $201.4(31.3)$ & $182.4(32.8)$ & $144.4(19.6)$ & 121.6 & $148.6(41.4)$ \\
\hline Time to peak velocity Unaffected & $224.2(14.5)$ & $216.6(35.9)$ & $224.2(14.5)$ & $186.2(63.7)$ & 243.2 & $156.5(35.8)$ \\
\hline Maximum Acceleration Affected & $58.4(27.9)$ & $52.4(18.5)$ & $59.1(7.5)$ & $65.5(19.2)$ & 75.2 & $70.3(33.4)$ \\
\hline Maximum Acceleration Unaffected & $40(10.8)$ & $51.1(6.9)$ & $61.9(5.9)$ & $55(11.1)$ & 39.5 & $61.9(30.3)$ \\
\hline Smoothness Affected & $5(2.8)$ & $4.7(0.5)$ & $2.2(0.9)$ & $2(1.4)$ & 4 & $3.2(1.6)$ \\
\hline Smoothness Unaffected & $3(0)$ & $3(0.8)$ & $2(0)$ & $2.2(0.5)$ & 2 & $2.7(1.2)$ \\
\hline
\end{tabular}

617 
Running head: TIME COURSE OF MOTOR GAINS INDUCED BY MUSIC-SUPPORTED THERAPY AFTER STROKE: AN EXPLORATORY CASE STUDY

623

624

625

626

627

630

631

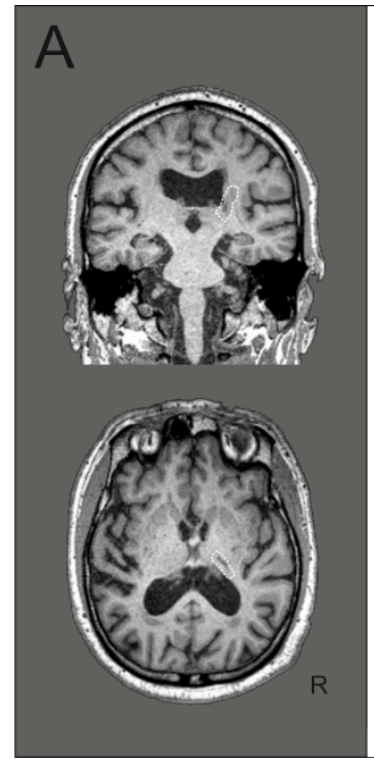

B

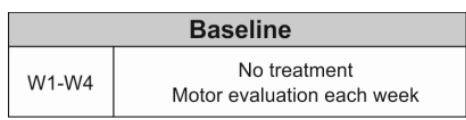

Motor evaluation each week
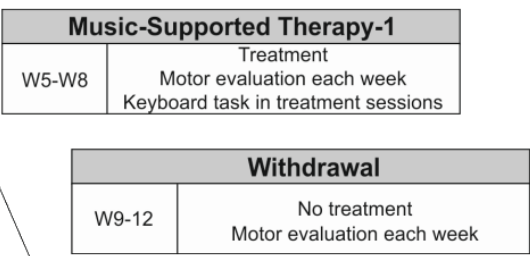

Music-Supported Therapy-2 \begin{tabular}{|c|c|} 
W13-16 & $\begin{array}{c}\text { Treatment } \\
\text { Motor evaluation each week } \\
\text { Keyboard task in treatment sessions }\end{array}$ \\
\hline
\end{tabular}

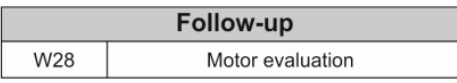

Motor evaluation

Clinical motor tests

Fugl-Meyer Assessment of Motor Recovery

Grip strength

Nine Hole Pegboard Test

Box and Blocks Test

Action Research Arm Test

Chedoke Arm and Hand Activity Inventory

3D Movement analysis

Finger and hand tapping tasks

Target reaching task

Music-Supported Therapy Protocol

12 sessions

- 3 sessions per week

(2) 3 (5) $1.5 \mathrm{~h}$ each session

45 min electronic drum set 
Running head: TIME COURSE OF MOTOR GAINS INDUCED BY MUSIC-SUPPORTED THERAPY AFTER STROKE: AN EXPLORATORY CASE STUDY

640 Figure 2. Results of the clinical motor tests. The most relevant findings regarding the clinical

641 evaluation are shown. The score obtained by the patient at each evaluation is displayed (weeks from

6421 to 16 and week 28). In each period, the mean of the participant was calculated (green line) and the

643 Minimal Detectable Change (MDC) or Minimal Clinically Important Difference (MCID) was added

644 to the mean baseline (orange line). A regression line considering all the data points was performed to

645 explore the tendency of the outcome across the different evaluations (blue line). $2 \mathbf{A}$. Results of the

646 grip strength for both extremities expressed in Kg. 2B. Results of the Box and Blocks Test. The

647 number of cubes that the patient is able to pass from one box to another in one minute is presented

648 for both extremities. 2C. Results of the Action Research Arm Test, which has a maximum

649 punctuation of 57. 2D. Results of the Chedoke Arm and Hand Activity Inventory. This test was

650 performed only during weeks $1,4,8,12$ and 16 and 28. The maximum punctuation is 91 . 


\section{Clinical motor tests}

\section{A. Grip Strength}

Affected Upper Extremity

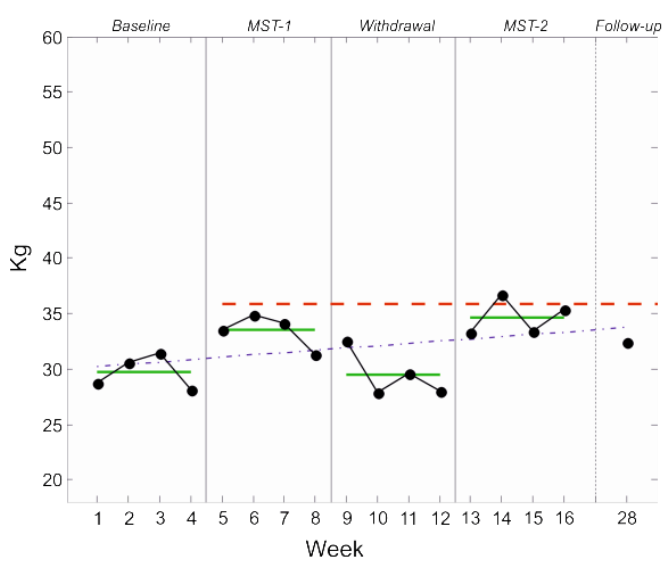

B. Box and Blocks Test

Affected Upper Extremity

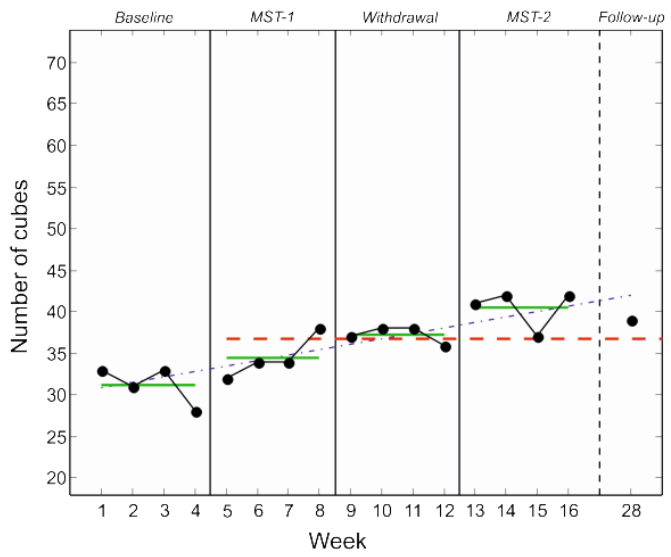

\section{Action Research Arm Test}

Affected Upper Extremity

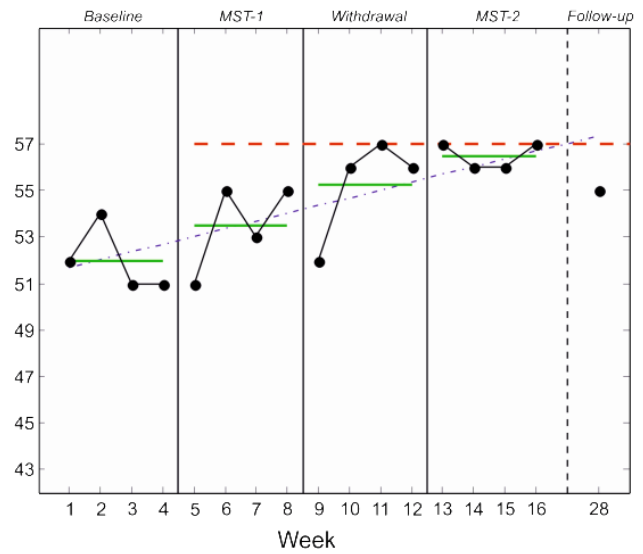

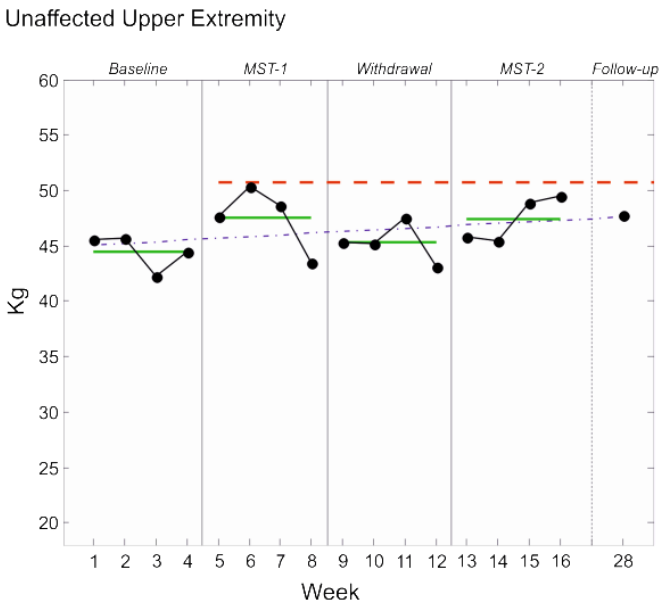

Unaffected Upper Extremity

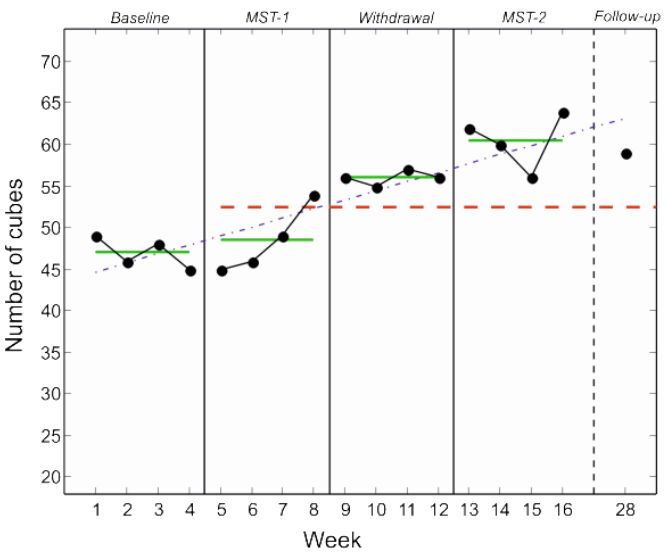

D. Chedoke Arm and Hand Activity Inventory

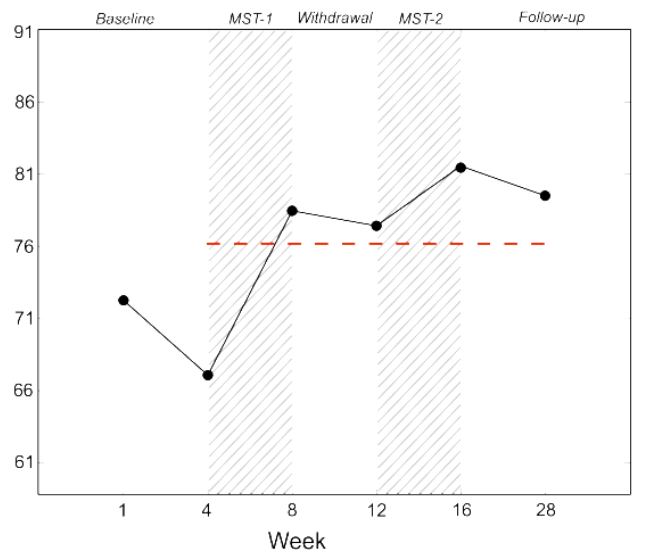


Running head: TIME COURSE OF MOTOR GAINS INDUCED BY MUSIC-SUPPORTED THERAPY AFTER STROKE: AN EXPLORATORY CASE STUDY

653

654

655

656

657

658

659

660

661

Figure 3. Results of the 3D movement analysis. The results of the finger and hand tapping, and a

reaching task are displayed for both extremities and each period (A.Baseline, B. MST-1, A.

Withdrawal, B. MST-2) and the follow-up evaluation (week 28). The mean of the controls and the

standard deviation of their performance at baseline are presented. 3A. Results of the finger tapping

task. 3B. Results of the hand tapping task. 3C. Results of the target reaching task. The frequency is expressed in $\mathrm{Hz}$, the mean velocity in $\mathrm{mm} / \mathrm{s}$, the time to peak velocity in $\mathrm{ms}$ and the maximum acceleration in $\mathrm{mm} / \mathrm{s}^{2}$. The smoothness is the number of velocity inversions per movement segment and typically is expected to be 1 .

\section{D Movement Analysis}

\section{A. Finger tapping}

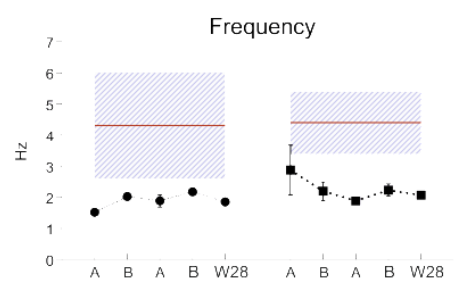

B. Hand tapping

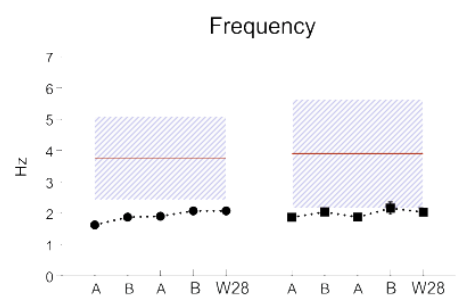

C. Target reaching

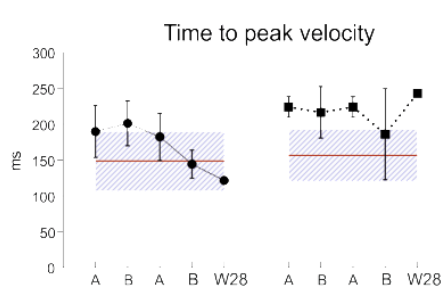

- Affected Upper Extremity

- Unaffected Upper Extremity

Controls mean (Baseline)

Controls standard deviation (Baseline)
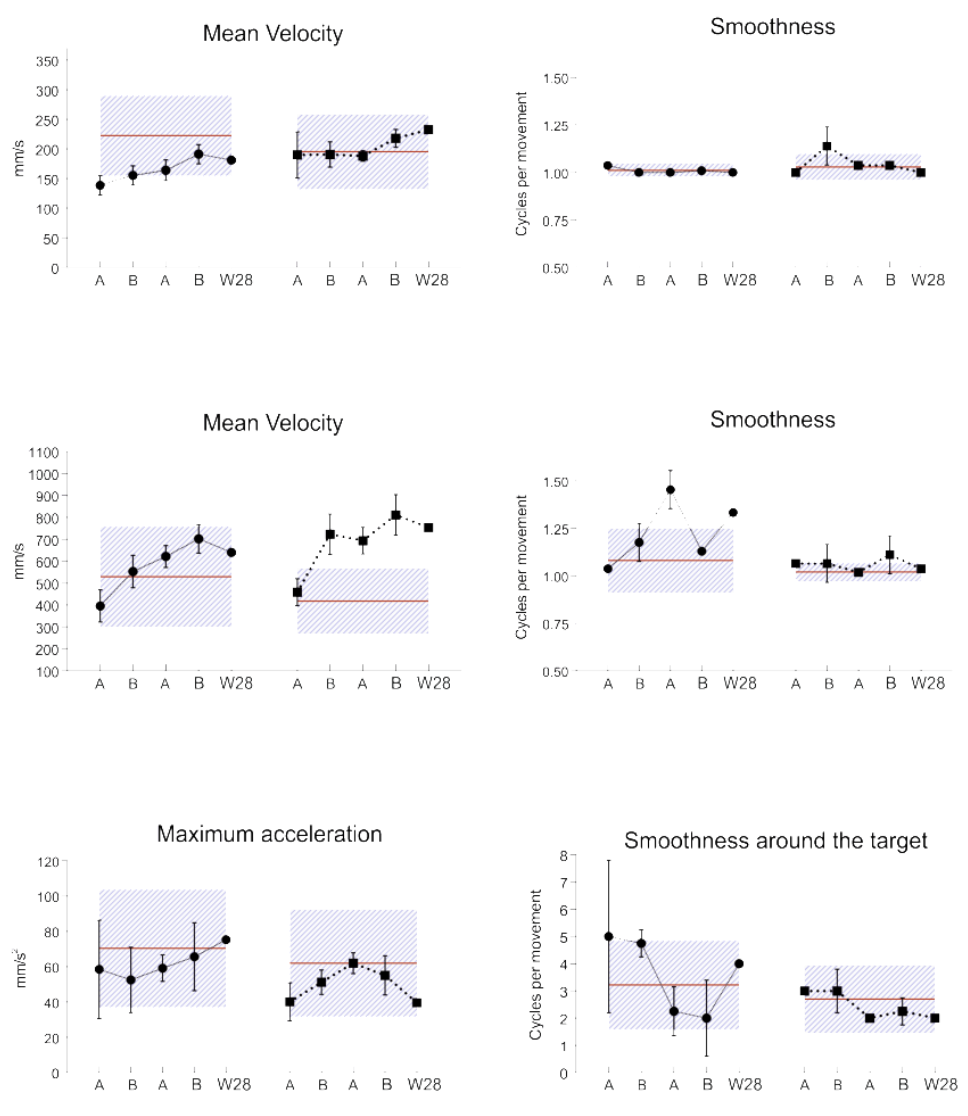
Running head: TIME COURSE OF MOTOR GAINS INDUCED BY MUSIC-SUPPORTED THERAPY AFTER STROKE: AN EXPLORATORY CASE STUDY

663

664

665

666

667

668

\section{Keyboard performance}

- MST-Period 1

a. MST-Period 2

- Controls mean (Baseline)

Controls standard deviation (Baseline)

\section{A. Sequence duration}

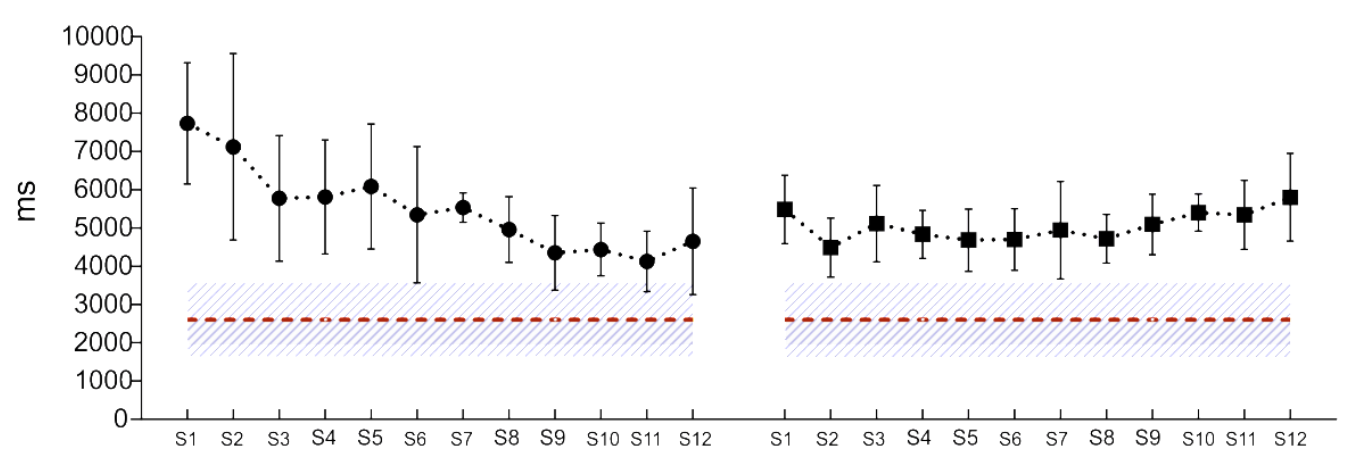

\section{B. Key pressure}

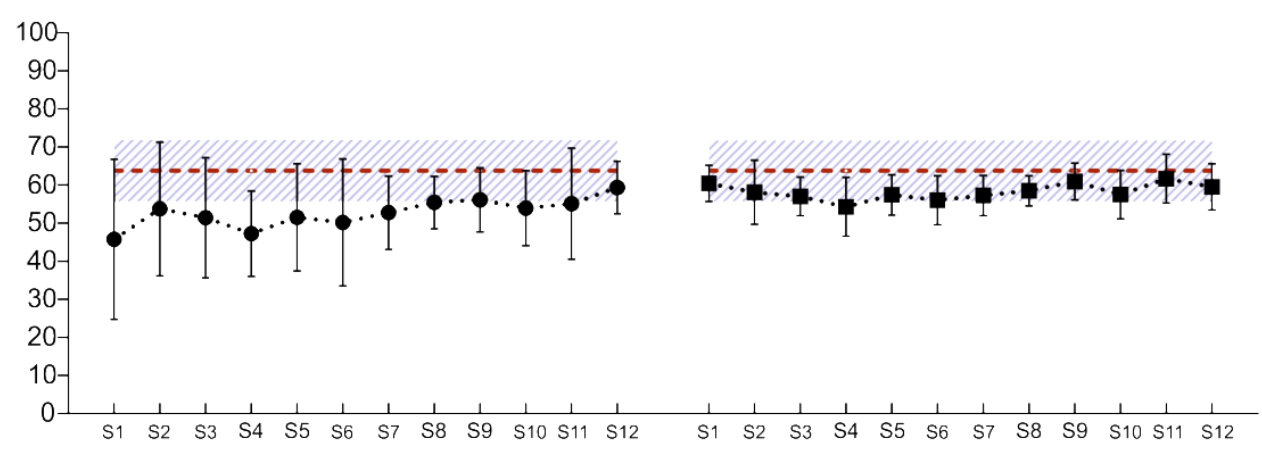

